\title{
A newly isolated Bacillus licheniformis strain thermophilically produces 2,3-butanediol, a platform and fuel bio-chemical
}

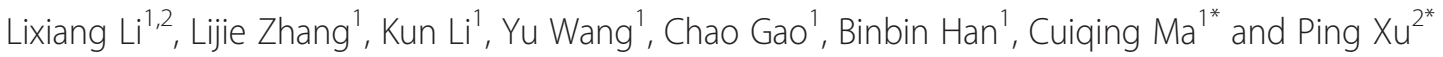

\begin{abstract}
Background: 2,3-Butanediol (2,3-BD), a platform and fuel bio-chemical, can be efficiently produced by Klebsiella pneumonia, K. oxytoca, and Serratia marcescens. However, these strains are opportunistic pathogens and not favorable for industrial application. Although some generally regarded as safe (GRAS) microorganisms have been isolated in recent years, there is still a demand for safe 2,3-BD producing strains with high productivity and yield under thermophilic fermentation.
\end{abstract}

Results: Bacillus licheniformis strain 10-1-A was newly isolated for 2,3-BD production. The optimum temperature and medium $\mathrm{pH}$ were $50^{\circ} \mathrm{C}$ and $\mathrm{pH} 7.0$ for 2,3-BD production by strain 10-1-A. The medium composition was optimized through Plackett-Burman design and response surface methodology techniques. With a two-stage agitation speed control strategy, $115.7 \mathrm{~g} / \mathrm{L}$ of 2,3-BD was obtained from glucose by fed-batch fermentation in a 5-L bioreactor with a high productivity (2.4 g/L-h) and yield (94\% of its theoretical value). The 2,3-BD produced by strain 10-1-A comprises $(2 R, 3 R)-2,3-\mathrm{BD}$ and meso-2,3-BD with a ratio of nearly 1:1. The bdh and gdh genes encoding meso-2,3-butanediol dehydrogenase (meso-BDH) and glycerol dehydrogenase (GDH) of strain 10-1-A were expressed in Escherichia coli and the proteins were purified. meso-2,3-BD and (2R,3R)-2,3-BD were transformed from racemic acetoin by meso-BDH and GDH with NADH, respectively.

Conclusions: Compared with the reported GRAS 2,3-BD producers, B. licheniformis 10-1-A could thermophilically produce 2,3-BD with a high concentration, productivity and yield. Thus, the newly isolated GRAS strain 10-1-A might be a promising strain for industrial production of 2,3-BD. Two key enzymes for meso-2,3-BD and (2R,3R)-2,3-BD production were purified and further studied, and this might be helpful to understand the mechanism for 2,3-BD stereoisomers forming in B. licheniformis.

Keywords: 2,3-butanediol, Bacillus licheniformis, Thermophilic fermentation, 2,3-butanediol dehydrogenase

\section{Background}

2,3-Butanediol (2,3-BD) is a crucial vicinal diol with 3 stereoisomers: meso-2,3-BD, $(2 R, 3 R)-2,3-\mathrm{BD}$, and (2S,3S)-2,3-BD. As an important commodity chemical, it can be used as the starting material for some bulk chemicals such as methyl ethyl ketone, gamma-butyrolactone and 1,3-butadiene [1-3]. It also has potential applications in the manufacture

\footnotetext{
*Correspondence: macq@sdu.edu.cn; pingxu@sjtu.edu.cn

'State Key Laboratory of Microbial Technology, Shandong University, Jinan 250100, People's Republic of China

${ }^{2}$ State Key Laboratory of Microbial Metabolism, and School of Life Sciences \& Biotechnology, Shanghai Jiao Tong University, Shanghai 200240, People's Republic of China
}

of food additives, cosmetics, printing ink, perfumes, drugs and explosives [4]. With a heating value of $27,200 \mathrm{~J} / \mathrm{g}$, 2,3-BD compares favourably with ethanol $(29,100 \mathrm{~J} / \mathrm{g})$ and methanol $(22,100 \mathrm{~J} / \mathrm{g})$ for using as a liquid fuel or fuel additive [4]. Enantio pure 2,3-BD, such as $(2 R, 3 R)-2,3-\mathrm{BD}$, can be used as an antifreeze agent [5]. In addition, meso-2,3$\mathrm{BD}$ can be used for the synthesis of renewable polyesters [6]. Nowadays, it is considered that the key downstream products of 2,3-BD have a potential global market of around 32 million tonnes per annum [1].

2,3-BD can be produced via chemical or biotechnological routes [2,3]. Due to the gradual exhaustion of crude oil reserves, interest in the biotechnological production of 2,3-BD has increased remarkably in recent years. Currently, Klebsiella

\section{Biomed Central}


pneumonia, K. oxytoca and Serratia marcescens are regarded as the most efficient 2,3-BD production strains that mainly produce meso-2,3-BD [7-9]. However, these strains are all categorized by the World Health Organization (WHO) as risk group 2 species (pathogenic) [4] and thus not desirable in industrial-scale production of 2,3-BD [1].

In recent years, some generally regarded as safe (GRAS) organisms including Bacillus licheniformis, Paenibacillus polymyxa (formerly B. polymyxa), and B. amyloliquefaciens have been isolated for 2,3-BD production [10-12]. Saccharomyces cerevisiae, $B$. licheniformis and $B$. subtilis have also been metabolically engineered to produce 2,3-BD [13-15]. The maximum 2,3-BD concentration obtained by a GRAS strain was $144.0 \mathrm{~g} / \mathrm{L}$, which was comparable with those achieved by the risk group 2 strains [10]. However, these reported GRAS strains for 2,3-BD production have optimal fermentation temperature of $30-40^{\circ} \mathrm{C}$. Due to the moderate temperature conditions, 2,3-BD fermentations can be easily contaminated [16]. Thermophilic fermentation, typically operated at $50-60^{\circ} \mathrm{C}$, can reduce the risk of bacterial contamination [17]. In addition, thermophilic fermentation is more efficient for utilization of lignocelluloses by simultaneous saccharification process [15]. Recently, Xiao et al. isolated a thermophilic strain, Geobacillus sp. XT15, for 2,3-BD and acetoin (AC) production [17]. However, the concentration, productivity and yield of the 2,3BD produced under thermophilic fermentation were rather low.

2,3-BD was produced from $\mathrm{AC}$, an intermediate of 2,3$\mathrm{BD}$ fermentation in microbes. Thus, 2,3-butanediol dehydrogenase $(\mathrm{BDH})$, which catalyzes the interconversion between $\mathrm{AC}$ and 2,3-BD, is a key enzyme for 2,3-BD production. Several BDHs with different stereospecificities have been purified and characterized in previous studies [18-24]. The meso-BDHs in K. pneumoniae, S. marcescens and Enterobacter cloacae belong to the short-chain dehydrogenase/reductase (SDR) family. In the presence of $\mathrm{NADH}$, all of three meso-BDHs could catalyze the conversion of (3R)-AC to meso-2,3-BD and (3S)-AC to $(2 S, 3 S)$ 2,3-BD [18,21,23]. The (2R,3R)-BDHs from P. polymyxa, $B$. subtilis, and $S$. cerevisiae belong to the medium-chain dehydrogenase/reductase family (MDR) [18]. These enzymes exhibited the abilities in interconversion of (3S)-AC/meso2,3-BD and (3R)-AC/(2R,3R)-2,3-BD [19,20,24]. On the other hand, it was reported that glycerol dehydrogenase (GDH) in Ogataea angusta could catalyze interconversion between (3R)-AC and $(2 R, 3 R)-2,3-\mathrm{BD}$ [25]. It might be another enzyme for 2,3-BD production.

In this work, a thermophilic GRAS strain B. licheniformis 10-1-A was newly isolated for 2,3-BD production. After statistical optimization of the fermentation medium composition and the culture conditions, 2,3-BD production was carried out in fed-batch fermentation by using two-stage agitation speed control strategy. In addition, the enzymes related to production of $(2 R, 3 R)-2,3-\mathrm{BD}$ and meso-2,3-BD in strain 10-1-A were also investigated.

\section{Results}

Isolation of thermophilic bacteria for 2,3-BD production

To screen a thermophilic strain for the production of 2,3-BD, about 63 isolates were obtained from 10 soil samples with deMan-Rogosa-Sharpe (MRS) medium at $50^{\circ} \mathrm{C}$. Strain $10-1-\mathrm{A}$ that produced the highest concentration of 2,3-BD was selected for further study.

Cells of the strain are a rod shaped, with cell diameters around $0.6-0.8 \mu \mathrm{m}$. The strain is Gram positive, starch hydrolysis positive, facultative growth positive, VogesProskauer (VP) reaction positive, and citrate utilization positive. The strain could grow in $6.5 \% \mathrm{NaCl}$ and at $55^{\circ} \mathrm{C}$. The partial $16 \mathrm{~S}$ rDNA sequence of strain 10-1-A (GenBank: JQ965662) is $100 \%$ identical with that of $B$. licheniformis strain CICC 10101 (GenBank: GQ375234). Based on the above results, strain 10-1-A was identified as a strain of $B$. licheniformis. This strain was deposited at the China General Microbiological Culture Collection Center (CGMCC 5461).

\section{Optimization of fermentation temperature}

The effect of temperature on the production of 2,3-BD was studied. Experiments were performed in the MRS medium at $37^{\circ} \mathrm{C}, 42^{\circ} \mathrm{C}, 50^{\circ} \mathrm{C}, 55^{\circ} \mathrm{C}$, and $60^{\circ} \mathrm{C}$, respectively. As shown in Figure 1, the highest concentration of 2,3$\mathrm{BD}, \quad 29.9 \pm 0.4 \mathrm{~g} / \mathrm{L}$, was obtained at $50^{\circ} \mathrm{C}$. This temperature was then selected for future investigations.

\section{Optimization of initial glucose concentration}

To select the initial carbon source concentration, the effect of glucose concentration on 2,3-BD production was investigated at initial $\mathrm{pH} 6.5,50^{\circ} \mathrm{C}$, and $180 \mathrm{rpm}$. As

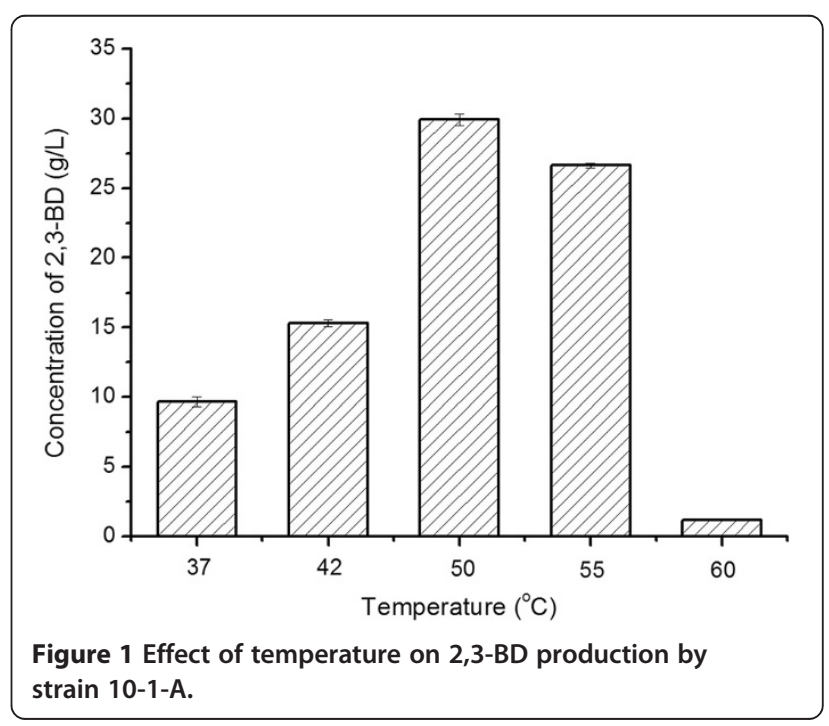


shown in Figure 2, with initial glucose concentrations lower than $125.0 \mathrm{~g} / \mathrm{L}$, similar concentrations of 2,3-BD were acquired. When the initial glucose concentration higher than $152.0 \mathrm{~g} / \mathrm{L}$, utilization of glucose was obviously inhibited and a small amount of 2,3-BD was produced. Initial glucose concentration between $64.0 \mathrm{~g} / \mathrm{L}$ and $125.0 \mathrm{~g} / \mathrm{L}$ was thus utilized in the successive studies.

\section{Selection of the organic nitrogen source}

Corn steep liquor powder (CSLP), an inexpensive organic nitrogen source available on a large scale, was used to replace the expensive organic nutrient in the selected medium. However, when yeast extract (YE), peptone, and beef extract in the fermentation medium were completely replaced with $10.0 \mathrm{~g} / \mathrm{L}$ CSLP, the concentration of 2,3-BD would decreased from $30.2 \pm 0.8 \mathrm{~g} / \mathrm{L}$ to $19.3 \pm$ $1.2 \mathrm{~g} / \mathrm{L}$ (Figure 3). To obtain high concentration of 2,3BD by using cheap CSLP as the major organic nitrogen source, $5.0 \mathrm{~g} / \mathrm{L}$ of YE, peptone or beef extract was added in the fermentation medium containing $10.0 \mathrm{~g} / \mathrm{L}$ of CSLP. The concentration of $2,3-\mathrm{BD}$ in the medium containing $5.0 \mathrm{~g} / \mathrm{L} \mathrm{YE}$ and $10.0 \mathrm{~g} / \mathrm{L}$ CSLP was higher than others. Thus, $5.0 \mathrm{~g} / \mathrm{L} \mathrm{YE}$ and $10.0 \mathrm{~g} / \mathrm{L}$ CSLP were chosen as the organic nitrogen source of the fermentation medium for future investigations.

\section{Statistical optimization of fermentation medium}

Phosphate, acetate, ammonium salt, $\mathrm{Mg}^{2+}$, YE and CSLP were used to compose the Plackett-Burman design (Table 1 and Table 2). Effects of the variables on the response and the significant levels are shown in Table 1.

To approach the neighborhood of the optimum response, a fitted first-order model was obtained from the Plackett-Burman experimental design as follows:

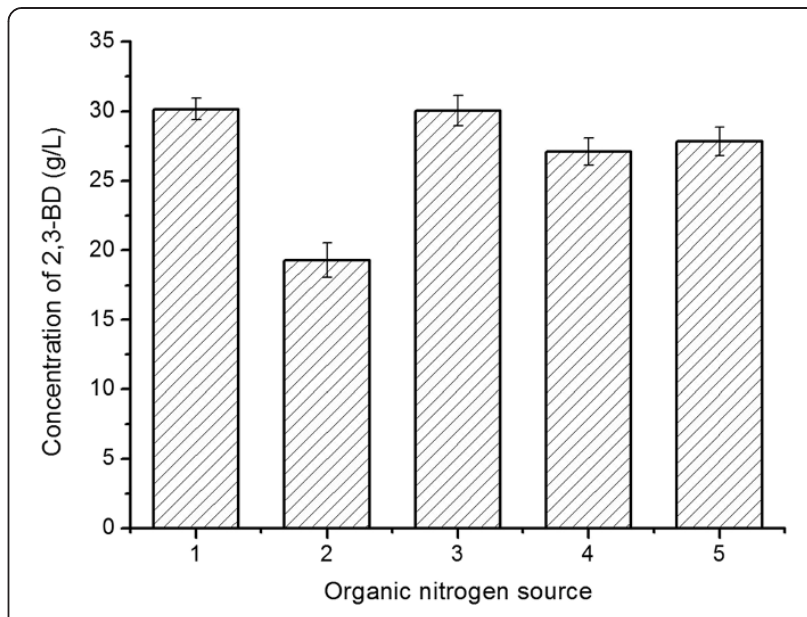

Figure 3 Effect of organic nitrogen source on 2,3-BD

production. $1,0.5 \%$ YE, $1 \%$ peptone and $1 \%$ beef extract; $2,1 \%$ CSLP; 3, $1 \%$ CSLP and $0.5 \%$ YE; 4, 1\% CSLP and $0.5 \%$ peptone; $5,1 \%$ CSLP and $0.5 \%$ beef extract. The experiments were conducted in 500-mL Erlenmeyer flasks containing $100 \mathrm{~mL}$ of each medium with shaking at $180 \mathrm{rpm}$ on a rotary shaker at $50^{\circ} \mathrm{C}$.

$$
\begin{aligned}
Y= & 27.16+2.06 X_{1}+2.34 X_{2}+2.32 X_{3} \\
& +1.05 X_{4}-1.16 X_{5}-0.57 X_{6}
\end{aligned}
$$

The coefficient of each variable represents its effect extent on the production of 2,3-BD. The linear regression coefficient $\left(R^{2}\right)$ is 0.9309 and the adjusted determination coefficient (Adj $R^{2}$ ) is 0.8480 for the model, indicating that the model would be reasonable for the PlackettBurman design.

Based on the statistical analysis, the factors having the greatest impacts on the production of 2,3-BD were identified as $X_{1}$ (YE, $\left.p=0.010\right), X_{2}($ CSLP, $p=0.006)$ and $X_{3}$
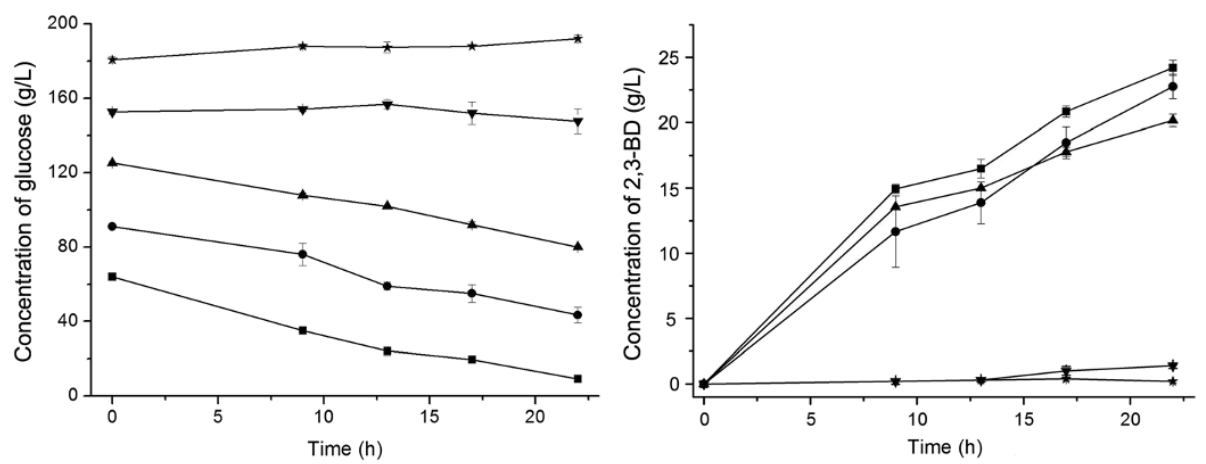

Figure 2 Effect of initial glucose concentration on 2,3-BD production by strain 10-1-A. The initial glucose concentrations used were at $64.0 \mathrm{~g} / \mathrm{L}(\mathbf{\bullet}), 91.0 \mathrm{~g} / \mathrm{L}(\bullet), 125.0 \mathrm{~g} / \mathrm{L}(\boldsymbol{\Delta}), 152.0 \mathrm{~g} / \mathrm{L}(\boldsymbol{\nabla})$ and $180.0 \mathrm{~g} / \mathrm{L}(\boldsymbol{\star})$. The experiments were conducted in 500-mL Erlenmeyer flasks containing $100 \mathrm{~mL}$ of each medium with shaking at $180 \mathrm{rpm}$ on a rotary shaker at $50^{\circ} \mathrm{C}$. 
Table 1 Plackett-Burman design for screening the variables, effect of each variable on 2,3-BD production, and statistical analysis of variables in the fermentation of glucose using strain 10-1-A

\begin{tabular}{lccccccc}
\hline Factor & Variable & Low level & High level & Coefficient & Standard error & $\boldsymbol{T}$-value & $\boldsymbol{P}$-value \\
\hline YE & $X_{1}$ & 2 & 4 & 2.061 & 0.5149 & 4 & $0.01^{\mathrm{a}}$ \\
CSLP & $X_{2}$ & 5 & 10 & 2.335 & 0.5149 & 4.53 & $0.006^{\mathrm{a}}$ \\
Sodium acetate & $X_{3}$ & 2 & 4 & 2.321 & 0.5149 & 4.51 & $0.006^{\mathrm{a}}$ \\
$\mathrm{K}_{2} \mathrm{HPO}_{4} \cdot 3 \mathrm{H}_{2} \mathrm{O}$ & $X_{4}$ & 2 & 4 & 1.051 & 0.5149 & 2.04 & 0.097 \\
Triammonium citrate & $X_{5}$ & 1 & 2 & -1.160 & 0.5149 & -2.25 & 0.074 \\
$\mathrm{MgSO}_{4} \cdot 7 \mathrm{H}_{2} \mathrm{O}$ & $X_{6}$ & 0.25 & 0.5 & -0.567 & 0.5149 & -1.1 & 0.321 \\
\hline
\end{tabular}

$R^{2}=0.9309, R^{2}($ Adj $)=0.8480$.

a Statistically significant at $95 \%$ of confidence level $(p<0.05)$.

(sodium acetate, $p=0.0050) . X_{4}\left(\mathrm{~K}_{2} \mathrm{HPO}_{4} \cdot 3 \mathrm{H}_{2} \mathrm{O}\right)$ was set at its high level according to its positive effect. $X_{5}$ (Triammonium citrate) and $X_{6}\left(\mathrm{MgSO}_{4} \cdot 7 \mathrm{H}_{2} \mathrm{O}\right)$ were set at their low levels according to their negative effects.

According to the above first-order equation, the steepest ascent direction is proportional to $(2.061,2.335,2.321)$, approximately equivalent to $(0.9,1.0,1.0)$. The design and responses of the steepest ascent experiment are shown in Table 3. The concentration of 2,3-BD was highest when the concentration of YE, CSLP and sodium acetate were selected as 5.7, 15.0 and $6.0 \mathrm{~g} / \mathrm{L}$, respectively. This combination was used as an appropriate center point for the central composition design (CCD) experiment. The design matrix of the variables together with the experimental responses is shown in Table 4.

The $p$-values were used as a tool to check the significance of each coefficient (Table 5). The smaller the $p$ value, the more significant is the corresponding coefficient [26]. Model terms are significant for values of $p$ less than 0.05 . According to these results, $X_{3}$ (sodium acetate),

Table 2 The level code for each variable in the PlackettBurman design and corresponding production response of 2,3-BD

\begin{tabular}{|c|c|c|c|c|c|c|c|}
\hline \multirow[t]{2}{*}{ Run } & \multicolumn{6}{|c|}{ Variable levels } & \multirow{2}{*}{$\begin{array}{c}2,3-B D \\
(g / L)\end{array}$} \\
\hline & $x_{1}$ & $x_{2}$ & $x_{3}$ & $X_{4}$ & $x_{5}$ & $x_{6}$ & \\
\hline 1 & 1 & -1 & 1 & -1 & -1 & -1 & $30.47 \pm 0.06$ \\
\hline 2 & 1 & 1 & -1 & 1 & -1 & -1 & $32.16 \pm 0.64$ \\
\hline 3 & -1 & 1 & 1 & -1 & 1 & -1 & $28.63 \pm 0.01$ \\
\hline 4 & 1 & -1 & 1 & 1 & -1 & 1 & $31.31 \pm 0.67$ \\
\hline 5 & 1 & 1 & -1 & 1 & 1 & -1 & $29.55 \pm 0.68$ \\
\hline 6 & 1 & 1 & 1 & -1 & 1 & 1 & $29.55 \pm 0.28$ \\
\hline 7 & -1 & 1 & 1 & 1 & -1 & 1 & $30.28 \pm 0.61$ \\
\hline 8 & -1 & -1 & 1 & 1 & 1 & -1 & $26.67 \pm 0.97$ \\
\hline 9 & -1 & -1 & -1 & 1 & 1 & 1 & $19.31 \pm 0.65$ \\
\hline 10 & 1 & -1 & -1 & -1 & 1 & 1 & $22.31 \pm 0.49$ \\
\hline 11 & -1 & 1 & -1 & -1 & -1 & 1 & $26.82 \pm 0.64$ \\
\hline 12 & -1 & -1 & -1 & -1 & -1 & -1 & $18.90 \pm 0.59$ \\
\hline
\end{tabular}

$X_{1}^{2}$ (YE), $X_{1} X_{2}, X_{2}^{2}$ (CSLP) and $X_{3}^{2}$ are significant model terms.

By applying multiple regression analysis to the experimental data, the following second-order polynomial equation was found:

$$
\begin{aligned}
Y= & 41.80+0.31 X_{1}-0.31 X_{2} \\
& +1.56 X_{3}-1.94 X_{1}^{2}-2.82 X_{2}^{2}-1.80 X_{3}^{2}-1.26 X_{1} X_{2} \\
& +0.15 X_{1} X_{3}-0.39 X_{2} X_{3}
\end{aligned}
$$

Where $Y$ is the predicted 2,3-BD production $(\mathrm{g} / \mathrm{L}) ; X_{1}$, $X_{2}$ and $X_{3}$ are the coded values of YE, CSLP and sodium acetate, respectively. The quality of fit of the quadratic regression model equation is expressed by the coefficient of determination $\left(R^{2}\right)$, which equals 0.9350 , indicating that $93.5 \%$ of the variability in the response could be explained by the model. The value of Adj $R^{2}(0.8766)$ is also very high to advocate for a high significance of the model. These results indicated that the response equation provides a suitable model for the CCD experiment.

The three-dimensional graph for the response surface model is shown in Figure 4. It is evident from the plot that 2,3-BD production has a maximum point in the studied region. When $X_{1}=0.1353$ (YE, $5.8 \mathrm{~g} / \mathrm{L}$ ), $X_{2}=-0.1162$ (CSLP, $14.7 \mathrm{~g} / \mathrm{L}$ ) and $X_{3}=0.4528$ (sodium acetate, $6.5 \mathrm{~g} / \mathrm{L}$ ), 2,3-BD concentration would reach the predicted maximum point (42.2 g/L).

In order to validate the adequacy of the model, the confirmation experiment was carried out at the predicted optimal condition. The mean concentration of

\begin{tabular}{|c|c|c|c|c|}
\hline Run & YE (g/L) & $\operatorname{CSLP}(g / L)$ & Sodium acetate $(\mathrm{g} / \mathrm{L})$ & 2,3-BD (g/L) \\
\hline 1 & 3 & 7.5 & 3 & 28.6 \\
\hline 2 & 3.9 & 10 & 4 & 32.6 \\
\hline 3 & 4.8 & 12.5 & 5 & 39.1 \\
\hline 4 & 5.7 & 15 & 6 & 41.3 \\
\hline 5 & 6.6 & 17.5 & 7 & 38.9 \\
\hline
\end{tabular}

Table 3 Experimental design and results of the steepest ascent 
Table 4 Experimental design and results of central composition experiment

\begin{tabular}{|c|c|c|c|c|c|}
\hline \multirow[t]{2}{*}{ Run } & \multicolumn{3}{|c|}{ Coded variable level } & \multicolumn{2}{|c|}{ 2,3-BD (g/L) } \\
\hline & $X_{1}$ & $x_{2}$ & $x_{3}$ & Observed & Predicted \\
\hline 1 & -1 & -1 & -1 & 32.2 & 32.2 \\
\hline 2 & 1 & -1 & -1 & 35.0 & 35.0 \\
\hline 3 & -1 & 1 & -1 & 34.0 & 34.9 \\
\hline 4 & 1 & 1 & -1 & 33.6 & 32.6 \\
\hline 5 & -1 & -1 & 1 & 35.7 & 35.8 \\
\hline 6 & 1 & -1 & 1 & 41.0 & 39.2 \\
\hline 7 & -1 & 1 & 1 & 37.9 & 36.9 \\
\hline 8 & 1 & 1 & 1 & 36.1 & 35.3 \\
\hline 9 & -1.682 & 0 & 0 & 36.2 & 35.8 \\
\hline 10 & 1.682 & 0 & 0 & 35.2 & 36.8 \\
\hline 11 & 0 & -1.682 & 0 & 33.8 & 34.4 \\
\hline 12 & 0 & 1.682 & 0 & 32.7 & 33.3 \\
\hline 13 & 0 & 0 & -1.682 & 34.5 & 34.1 \\
\hline 14 & 0 & 0 & 1.682 & 37.7 & 39.3 \\
\hline 15 & 0 & 0 & 0 & 41.3 & 41.8 \\
\hline 16 & 0 & 0 & 0 & 43.0 & 41.8 \\
\hline 17 & 0 & 0 & 0 & 40.7 & 41.8 \\
\hline 18 & 0 & 0 & 0 & 42.7 & 41.8 \\
\hline 19 & 0 & 0 & 0 & 41.6 & 41.8 \\
\hline 20 & 0 & 0 & 0 & 41.8 & 41.8 \\
\hline
\end{tabular}

the obtained 2,3-BD from triplicate trials in shaking flask was $42.3 \pm 1.4 \mathrm{~g} / \mathrm{L}$, which is near the predicted value $(42.2 \mathrm{~g} / \mathrm{L})$.

\section{Effect of $\mathrm{pH}$ on 2,3-BD production}

The effects of $\mathrm{pH}(6.5-8.0)$ of the culture medium on glucose utilization and 2,3-BD production were investigated. The experiments were carried out with $105.0 \mathrm{~g} / \mathrm{L}$

Table 5 Significance test of regression coefficient of the central composition experiment

\begin{tabular}{lcccc}
\hline Variable & Coefficient & Standard error & $\boldsymbol{T}$-value & $\boldsymbol{P}$-value \\
\hline Intercept & 41.8017 & 0.5181 & 80.6810 & 0.0002 \\
$X_{1}$ & 0.3089 & -0.3440 & 0.8979 & 0.3903 \\
$X_{2}$ & -0.3078 & -0.3440 & -0.8946 & 0.3920 \\
$X_{3}$ & 1.5652 & -0.3440 & 4.5496 & $0.0010^{\mathrm{a}}$ \\
$X_{1}^{2}$ & -1.9426 & -0.3440 & -5.8005 & $0.0002^{\mathrm{a}}$ \\
$X_{1} X_{2}$ & -1.2662 & 0.4495 & -2.8170 & $0.0182^{\mathrm{a}}$ \\
$X_{1} X_{3}$ & 0.1538 & 0.4495 & 0.3420 & 0.7394 \\
$X_{2}^{2}$ & -2.8194 & 0.3349 & -8.4185 & $0.0001^{\mathrm{a}}$ \\
$X_{2} X_{3}$ & -0.3888 & 0.4495 & -0.8649 & 0.4074 \\
$X_{3}^{2}$ & -1.8012 & 0.3349 & -5.3782 & $0.0003^{\mathrm{a}}$ \\
\hline $\mathrm{R}^{2}=0.9350, \mathrm{R}^{2}$ & & &
\end{tabular}

$R^{2}=0.9350, R^{2}($ Adj) $=0.8766$.

${ }^{\text {a }}$ Statistically significant at $95 \%$ of confidence level $(p<0.05)$. glucose for $11 \mathrm{~h}$ in a 1-L bioreactor with $0.8 \mathrm{~L}$ initial medium. The results are summarized in Table 6. 2,3-BD production by $B$. licheniformis 10-1-A is obviously $\mathrm{pH}-$ dependent with the maximum productivity at $\mathrm{pH}$ 7.0. The yield of 2,3-BD under the low $\mathrm{pH}$ is above $100 \%$ of the theoretical yield, which might be caused by the addition of acetic acid in the fermentation process. Thus, pH 7.0 was chosen for further experiments.

\section{Two-stage agitation speed control strategy for 2,3-BD fermentation}

Fed-batch fermentation was performed in a 5-L bioreactor by using the optimal medium at $\mathrm{pH} 7.0$, and different agitation speed control strategies were used. When the agitation speed was $400 \mathrm{rpm}$, the AC increased quickly in the stabilization phase that lead to a low yield of 2,3-BD (Table 7). Meanwhile, when the agitation speed was $200 \mathrm{rpm}$, formic acid increased quickly after $2 \mathrm{~h}$ to a high concentration of $42.0 \mathrm{~g} / \mathrm{L}$ at the end of fermentation (Table 7). This also decreased the yield of 2,3-BD. To overcome these problems, a two-stage agitation speed control strategy for 2,3-BD fermentation was used. In first $10 \mathrm{~h}$, the agitation speed was $400 \mathrm{rpm}$, and then it was decreased to $200 \mathrm{rpm}$. As shown in Figure 5, the feeding started at $6 \mathrm{~h}$ when the residual glucose concentration was below $20.0 \mathrm{~g} / \mathrm{L}$. The curve of 2,3-BD production can be divided into two parts (Figure 5). In the first $20 \mathrm{~h}, 85.0 \mathrm{~g} / \mathrm{L}$ of 2,3-BD was produced and the average productivity reached $4.3 \mathrm{~g} / \mathrm{L} \cdot \mathrm{h}$. From $20 \mathrm{~h}$ to $48 \mathrm{~h}$, the concentration of 2,3-BD climbed from $85.0 \mathrm{~g} / \mathrm{L}$ to $115.7 \mathrm{~g} / \mathrm{L}$ and the average productivity was $1.1 \mathrm{~g} / \mathrm{L} \cdot \mathrm{h}$. At the end of the fed-batch fermentation, $115.7 \mathrm{~g} / \mathrm{L}$ of 2,3-BD was obtained from $246.0 \mathrm{~g} / \mathrm{L}$ glucose after $48 \mathrm{~h}$ of fermentation at $50^{\circ} \mathrm{C}$. The yield of 2,3-BD produced by $B$. licheniformis 10-1-A was $94 \%$ of the theoretical value and the average productivity of 2,3-BD was $2.4 \mathrm{~g} / \mathrm{L} \cdot \mathrm{h}$. Formic acid was the main byproduct and its concentration was $28.3 \mathrm{~g} / \mathrm{L}$ at $48 \mathrm{~h}$. The time course of other by-products was shown in Figure 5. Lactic acid $(2.0 \mathrm{~g} / \mathrm{L})$ was depleted in the process. The acetic acid was used as the neutralizer in the fermentation process while the concentration of acetic acid was maintained at about $4.0 \mathrm{~g} / \mathrm{L}$.

\section{Stereoisomeric composition analysis of 2,3-BD produced by strain 10-1-a}

The stereoisomeric composition of 2,3-BD formed by bacteria differs among strains. The 2,3-BD produced by strain 10-1-A was analyzed by GC with a flame ionization detector and a fused silica capillary column [24]. It was found that there was a mixture of $(2 R, 3 R)-2,3-\mathrm{BD}$ and meso-2,3-BD with a ratio of nearly $1: 1$ in the broth as shown in Figure 6.

Genome sequence of strain 10-1-A contains a complete alsSD operon for (3R)-AC production [27]. 

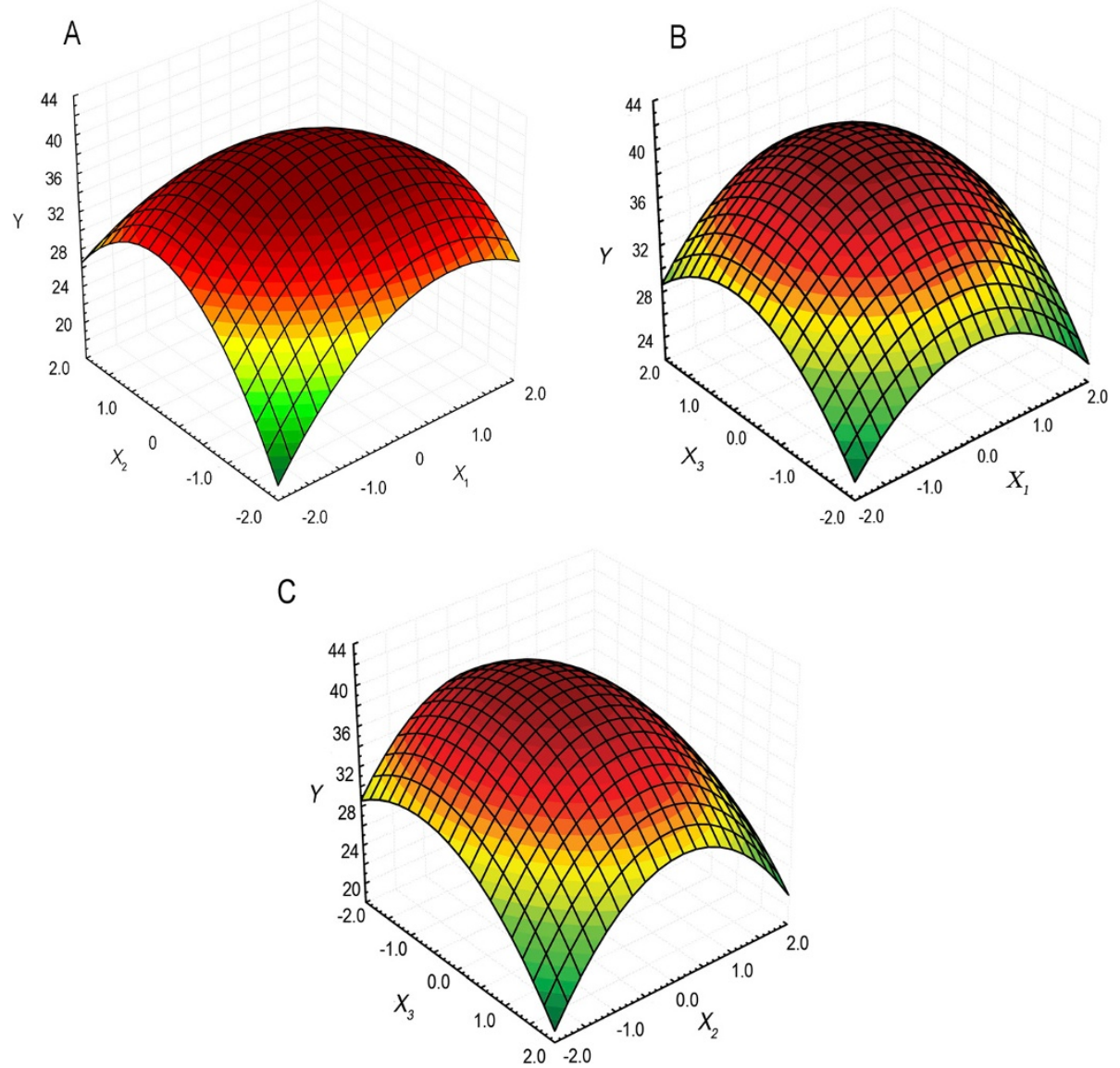

Figure 4 The response surface plot. A, effects of YE and CSLP on 2,3-BD production. B, effects of YE and sodium acetate on 2,3-BD production. C, effects of CSLP and sodium acetate on 2,3-BD production.

Since $(2 R, 3 R)-2,3-\mathrm{BD}$ and meso-2,3-BD could be produced from $(3 R)-\mathrm{AC}$ by $(2 R, 3 R)-\mathrm{BDH}$ and meso-BDH, respectively, the putative $(2 R, 3 R)-\mathrm{BDH}$ and meso-BDH encoding genes in strain 10-1-A were analyzed based on multiple sequence alignment and phylogenetic tree analysis (Additional file 1: Figure S1).

The enzymes encoding by bdh (GenBank: KF250429) and $g d h$ (GenBank: KF250430) were suspected to be able to catalyze $\mathrm{AC}$ to 2,3-BD and these genes were cloned and expressed in Escherichia coli (BL21). Both of the enzymes were purified and detected by sodium dodecyl sulfate polyacrylamide gel electrophoresis (SDS-PAGE) as shown in (Figure 7A and C). When $100 \mathrm{mM} \mathrm{AC}$ was incubated with $100 \mathrm{mM} \mathrm{NADH}$ and $10 \mathrm{U}$ purified meso-BDH for $30 \mathrm{~min}$ in $50 \mathrm{mM}$ Tris- $\mathrm{HCl}$ buffer (pH 7.4), meso-2,3-BD and a little (2S,3S)-2,3-BD were produced (Figure 7B). While the purified GDH was used under the same conditions as assaying meso-BDH, $(2 R, 3 R)-2,3-\mathrm{BD}$ and a little meso-2,3-BD were produced (Figure 7D).

\section{Discussion}

Thermophilic fermentation can reduce the risk of bacterial contamination, and can even be operated without sterilization [28], making it more efficient and cost-

Table 6 Effect of pH on 2,3-BD production by B. licheniformis 10-1-A

\begin{tabular}{|c|c|c|c|c|c|c|c|c|c|}
\hline \multirow[t]{2}{*}{$\mathrm{pH}$} & \multirow{2}{*}{$\begin{array}{c}\text { Glucose } \\
\text { consumed } \\
(\mathrm{g} / \mathrm{L})\end{array}$} & \multicolumn{6}{|c|}{ Products (g/L) } & \multirow{2}{*}{$\begin{array}{c}\text { Yield } \\
(\%)\end{array}$} & \multirow{2}{*}{$\begin{array}{l}\text { Productivity } \\
\text { (g/L·h) }\end{array}$} \\
\hline & & 2,3-BD & $A C$ & Lactic acid & Formic acid & Acetic acid & Ethanol & & \\
\hline 6.5 & 74.0 & 36.6 & 0.6 & 1.2 & 1.5 & 5.5 & 4.1 & 100.7 & 3.3 \\
\hline 7.0 & 99.0 & 49.6 & 1.8 & 1.3 & 1.3 & 4.9 & 8.3 & 100.4 & 4.6 \\
\hline 7.5 & 92.0 & 41.2 & 0.8 & 8.1 & 15.2 & 1.2 & 3.6 & 91.4 & 3.8 \\
\hline 8.0 & 43.0 & 4.5 & 0.1 & 15.5 & 1.5 & 4.0 & 1.9 & 21.2 & 0.4 \\
\hline
\end{tabular}


Table 7 2,3-BD fermentation by strain 10-1-A with different agitation speed control strategies

\begin{tabular}{cccccccccc}
\hline $\begin{array}{c}\text { Control } \\
\text { strategy }\end{array}$ & $\begin{array}{c}\text { Glucose } \\
\text { consumed } \\
\mathbf{( g / L )}\end{array}$ & $\mathbf{2 , 3 - B D}$ & $\mathbf{A C}$ & Lactic acid & Formic acid & Acetic acid & Ethanol & $\begin{array}{c}\text { Pield } \\
(\%)\end{array}$ & $\begin{array}{c}\text { Productivity } \\
(\mathbf{g} / \mathbf{L} \cdot \mathbf{h})\end{array}$ \\
\hline A & 189 & 81.0 & 0.9 & 0.8 & 42 & 2.2 & 1.8 & 85.7 \\
B & 185 & 45.7 & 45.1 & 0 & 1.2 & 3.3 & 0.6 & 49.4 & 1.6 \\
C & 246 & 115.7 & 2.2 & 0 & 28.3 & 4.8 & 1.1 & 94.1 & 2.4 \\
\hline
\end{tabular}

A: the agitation speed was $200 \mathrm{rpm}$ in the course; B: the agitation speed was $400 \mathrm{rpm}$ in the course; C: the agitation speed was $400 \mathrm{rpm}$ in the first $10 \mathrm{~h}$ and then decreased to $200 \mathrm{rpm}$.

effective. In addition, thermophilic fermentation matches the simultaneous saccharification process for utilization of lignocelluloses, which has the best efficiency around $50^{\circ} \mathrm{C}$ [15]. Thus, isolation of thermophilic strains for lactic acid, ethanol and 2,3-BD production has gained considerable attention [15,17,28-30]. Wang et al. reported the first high temperature fermentation of 2,3-BD by using a genetically engineered $B$. licheniformis strain BL5 in which the $l d h$ gene was knocked out [15]. The concentration of 2,3-BD produced by B. licheniformis BL5 was $12.1 \mathrm{~g} / \mathrm{L}$. Xiao et al. isolated a thermophilic Geobacillus strain XT15 and found it is an AC and 2,3$\mathrm{BD}$ producer. The concentration of $2,3-\mathrm{BD}$ produced by strain XT15 was $14.5 \mathrm{~g} / \mathrm{L}$ [17]. In this work, a $B$. licheniformis strain 10-1-A was isolated for 2,3-BD production. In MRS medium, the concentration of 2,3-BD obtained by strain $10-1-\mathrm{A}$ at $50^{\circ} \mathrm{C}$ was about $30.0 \mathrm{~g} / \mathrm{L}$. Strain 10-1-A might be a promising thermophilic strain and thus the conditions for 2,3-BD production by the strain were optimized.

Statistically based experimental designs were used to find an appropriate fermentation medium for strain 10-1-A. During the optimization process, CSLP, an inexpensive valuable nutrient source available on a large scale, was used as the major nitrogen source to replace the expensive nutrient source. The 2,3-BD concentration in the optimized medium is 1.4-fold than that of MRS medium. Then, the operating conditions for 2,3-BD production from glucose by strain 10-1-A was also optimized. It was reported that $\mathrm{pH} 6.0$ was the optimal condition for production of 2,3-BD by $B$. licheniformis [31]. For B. licheniformis $\mathrm{BL} 5, \mathrm{pH} 5.0$ was regarded as the optimum $\mathrm{pH}$ for 2,3-BD production [15]. The results in this study shows that $\mathrm{pH}$ was also a major influence on 2,3-BD production and $\mathrm{pH} 7.0$ was optimum for strain 10-1-A. Oxygen supply is another important variable in the 2,3-BD fermentation which could affect product yield, productivity, and byproducts formation [3,4]. Agitation speed control was found to be a simple method to adjust oxygen supply and realize efficient 2,3-BD fermentation [7]. In this work, a two-stage agitation speed control strategy was found to be more suitable for 2,3-BD fermentation by strain 10-1-A (Table 7). Under optimum conditions, $115.7 \mathrm{~g} / \mathrm{L}$ of 2,3-BD was obtained from $246.0 \mathrm{~g} / \mathrm{L}$ glucose after $48 \mathrm{~h}$ of fermentation by using the novel strain 10-1-A.

Due to their GRAS status, the 2,3-BD produced by $B$. licheniformis, $P$. polymyxa, and B. amyloliquefaciens might afford the demand for the production of food additives or cosmetics (Table 8). Although $P$. polymyxa DSM365 produced 2,3-BD with a high concentration of
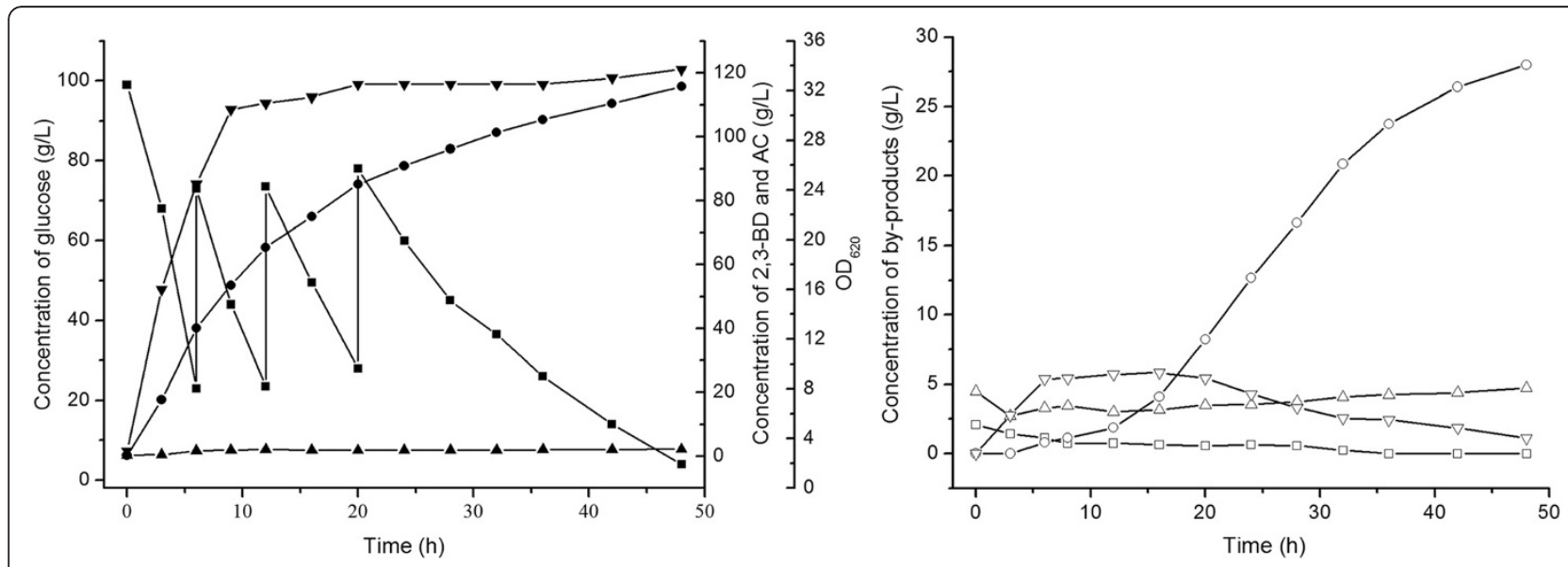

Figure 5 Time course of fed-batch fermentation of 2,3-BD. Biomass $(\boldsymbol{\nabla}), 2,3-B D(\bullet)$, glucose $(\mathbf{\square})$, AC $(\mathbf{\Delta})$, acetic acid $(\Delta)$, lactic acid ( $\square$ ), ethanol $(\nabla)$ and formic acid (o). The fermentation was carried out at $50^{\circ} \mathrm{C}$ in a 5 - L bioreactor with $\mathrm{pH}$ control by automatic addition of $6 \mathrm{M}$ acetic acid and $\mathrm{NaOH}$, stirring at $400 \mathrm{rpm}$ in the first $10 \mathrm{~h}$ and then decreased to $200 \mathrm{rpm}$, and airflow at $1.0 \mathrm{vvm}$. 


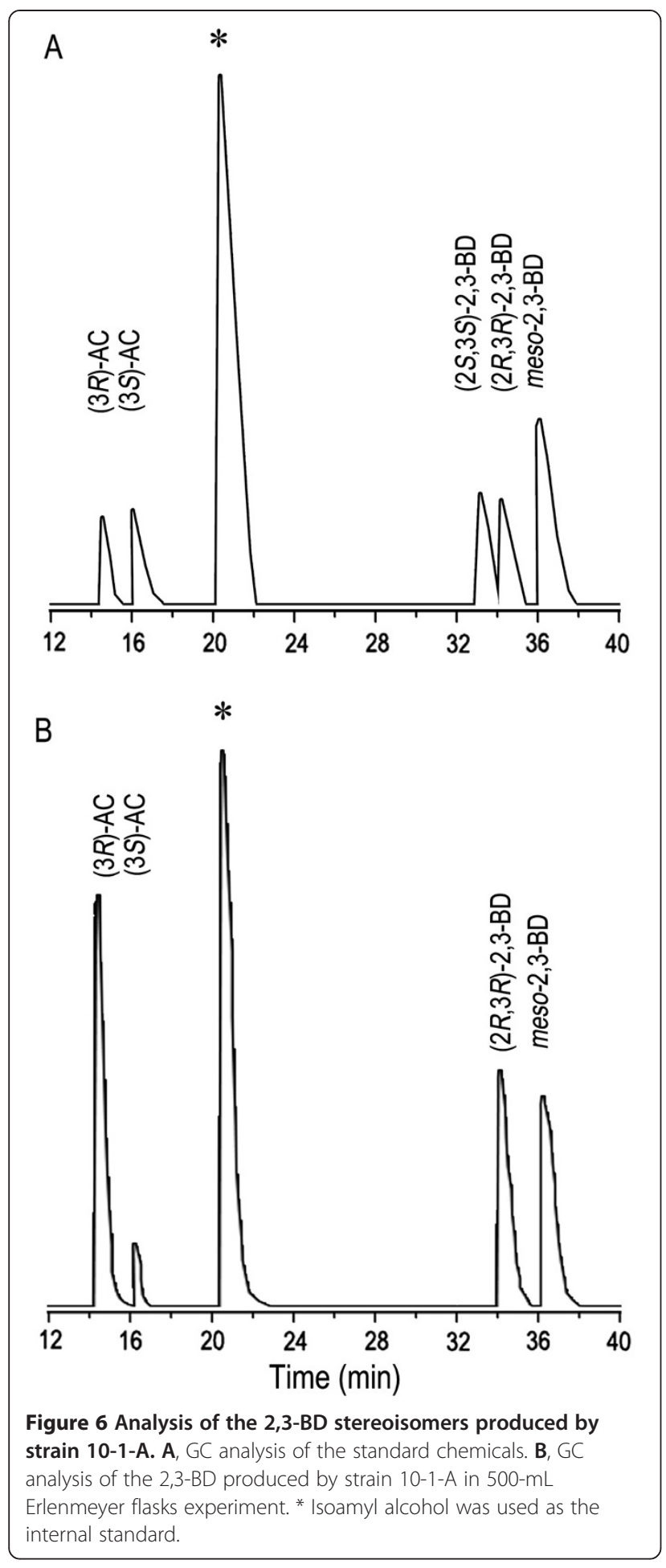

$111.0 \mathrm{~g} / \mathrm{L}$, the fermentation process needed addition of $60.0 \mathrm{~g} / \mathrm{L}$ YE. B. licheniformis DSM8785 also produced 2,3-BD with a rather high concentration $(144.7 \mathrm{~g} / \mathrm{L})$, but the productivity of the strain was unsatisfactory. B. licheniformis 10-1-A produced 2,3-BD with a yield of $94 \%$ and an average productivity of $2.4 \mathrm{~g} / \mathrm{L} \cdot \mathrm{h}$. As shown in Table 8 , the yield and productivity of strain 10-1-A are both the new record of 2,3-BD production by GRAS strain.

The high yield of strain 10-1-A would not only decrease the substrate cost but also make the downstream processing much easy and inexpensive to perform. The high productivity of strain 10-1-A might be a result of the high metabolic rate at its relatively high optimal fermentation temperature. As shown in Table 8, as a novel GRAS strain, B. licheniformis 10-1-A produced 2,3-BD with a productivity that compares favourably with those of risk group 2 species. Thus, although pathogenic K. pneumonia, K. oxytoca, Enterobacter cloacae and S. marcescens produced 2,3-BD with higher concentrations $[8,9,32,33]$, the thermophilic $B$. licheniformis strain is still a very promising alternative for the large scale production of 2,3-BD.

All of the isomers of 2,3-BD including $(2 R, 3 R)-2,3-\mathrm{BD}$, (2S,3S)-2,3-BD and meso-2,3-BD are important potential chemical intermediates. Different microorganisms produce different stereoisomers of 2,3-BD [18]. Thus, isomers formation mechanisms and the key enzymes in different 2,3-BD producers such as $K$. pneumonia, $P$. polymyxa and $S$. marcescens have been studied to make the fermentation process more clearly and efficiently $[18,19,23]$. However, the 2,3-BD formation mechanism in $B$. licheniformis, a very promising 2,3-BD producer, has never been studied until now.

Based on the genome sequence of thermophilic B. licheniformis strain 10-1-A [27], the key enzymes involved in 2,3-BD formation were analyzed. A complete alsSD operon was found in the genome of the strain. The alsS gene may encode an $\alpha$-acetolactate synthase that catalyzes the conversion of pyruvate to $\alpha$-acetolactate. The $a l s D$ gene may encode an $\alpha$-acetolactate decarboxylase that catalyzes the conversion of $\alpha$-acetolactate to (3R)-AC. The alsR gene, which is located upstream of the alsSD operon, may encode the transcriptional regulator AlsR. The protein sequences of these genes exhibit high identities with those of $K$. pneumonia, B. subtilis, E. cloacae and $S$. marcescens (Additional file 2: Figure S2). Since the reaction catalyzed by $\alpha$-acetolactate decarboxylase is stereospecific and only leads to the formation of the (3R)-AC [34], stereospecificity of the BDH has been accepted as a key factor for 2,3-BD isomers formation in K. pneumonia, $P$. polymyxa, E. cloacae and S. marcescens. Thus, the putative BDH in strain 10-1-A was studied detailedly in this work.

Strains of Bacillus sp., such as $P$. polymyxa, produced $(2 R, 3 R)-2,3-\mathrm{BD}$ as the major product, $(2 R, 3 R)-\mathrm{BDH}$ was found to be responsible for the production of $(2 R, 3 R)-2,3-$ $\mathrm{BD}$ in P. polymyxa [19]. Some pathogenic strains including $K$. pneumonia, E. cloacae and S. marcescens produce meso-2,3-BD as the major product. The meso-BDHs are responsible for production of meso-2,3-BD in those strains 


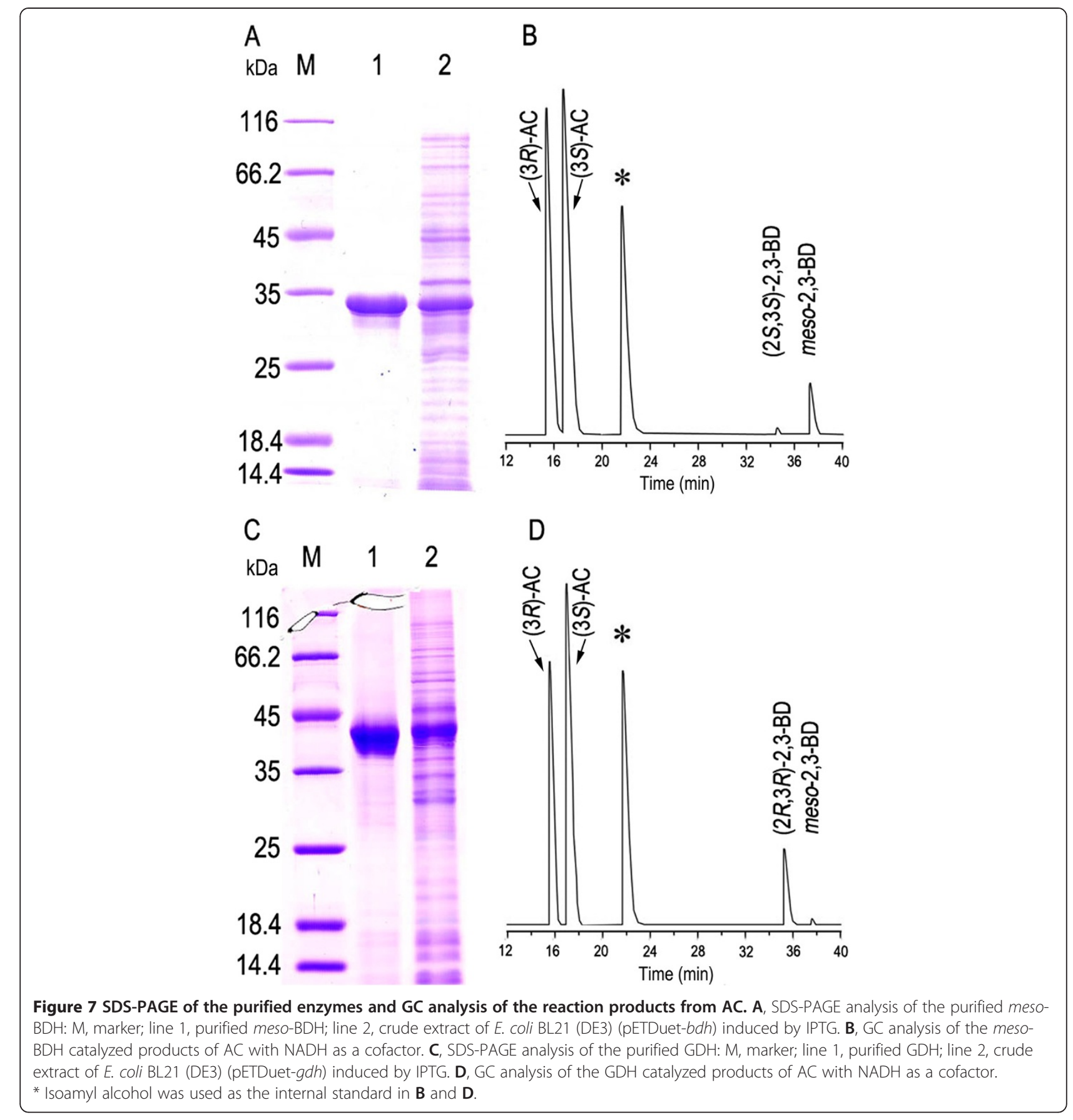

$[18,21,23]$. As shown in Figure 6, different from all the reported 2,3-BD producing strains mentioned above, strain $10-1$-A produced a mixture of $(2 R, 3 R)-2,3-\mathrm{BD}$ and meso-2,3-BD with a ratio of nearly $1: 1$. As $(3 R)$-AC would be the major source of $(2 R, 3 R)-2,3-\mathrm{BD}$ and meso-2,3-BD, a meso-BDH (catalyzing (3R)-AC into meso-2,3-BD) and a $(2 R, 3 R)-\mathrm{BDH}$ (catalyzing ( $3 R)-\mathrm{AC}$ into $(2 R, 3 R)-2,3-\mathrm{BD})$ would be co-present in strain 10-1-A.

After analysis of the genome sequence, a $b d h$ gene encoding a meso-BDH of SDR family was found in the genome of strain 10-1-A. Its protein sequence exhibits $67.7 \%$ identity with that of $K$. pneumonia IAM1063 (Additional file 1: Figure S1). This enzyme was purified and its stereospecificity was studied. meso-2,3-BD was found to be the major product from racemic AC. This property is similar to the meso-BDH in $S$. marcescens which is key enzyme for meso-2,3-BD production [18].

No gene exhibiting high identity with $(2 R, 3 R)$-BDHs of P. polymyxa ATCC12321, B. subtilis 168, and S. cerevisiae, was found in the genome sequence of strain 10-1-A. 
Table 8 Comparison of the 2,3-BD production using different microorganisms

\begin{tabular}{|c|c|c|c|c|c|}
\hline Strain & $\begin{array}{c}\text { Temperature } \\
\left({ }^{\circ} \mathrm{C}\right)\end{array}$ & $\begin{array}{c}\text { Concentration } \\
(\mathrm{g} / \mathrm{L})\end{array}$ & $\begin{array}{c}\text { Productivity } \\
\text { (g/L·h) }\end{array}$ & $\begin{array}{c}\text { Yield } \\
(\%)\end{array}$ & Reference \\
\hline B. amyloliquefaciens & 37 & 92.3 & 0.96 & 84 & 12 \\
\hline B. subtilis & 37 & 6.1 & 0.4 & 67 & 13 \\
\hline S. cerevisia & ND & 2.3 & 0.03 & 22.6 & 14 \\
\hline P. polymyxa & 30 & 111 & 2.06 & ND & 11 \\
\hline Geobacillus sp. & 55 & 14.5 & 0.30 & 69 & 17 \\
\hline B. licheniformis & 30 & 144.7 & 1.14 & 80 & 10 \\
\hline B. licheniformis & 50 & 12.1 & 1.01 & 90 & 15 \\
\hline S. marcescens & 30 & 152 & 2.67 & 82 & 9 \\
\hline K. oxytoca & 37 & 130 & 1.64 & 96 & 32 \\
\hline K. pneumoniae & 37 & 150 & 4.21 & 86 & 8 \\
\hline B. licheniformis & 50 & 115 & 2.4 & 94 & This study \\
\hline
\end{tabular}

Glycerol is a vicinal diol with a similar structure to 2,3-BD except the first hydroxyl group. It was reported that GDH in $O$. angusta had the ability to catalyze interconversion between (3R)-AC and (2R,3R)-2,3-BD and this enzyme showed greater activity towards $(2 R, 3 R)-2,3-\mathrm{BD}$ than towards glycerol [25]. This indicated that GDH might play a role in 2,3-BD formation. Thus, the gdh gene encoding a GDH of MDR family in strain 10-1-A was also cloned and expressed in E. coli (Additional file 1: Figure S1). Although the protein sequence of GDH in strain 10-1-A is only $11.8 \%$ identity with that of $O$. angusta (BAD32688.1), the enzyme could also catalyze the production of $(2 R, 3 R)-2,3-$ $\mathrm{BD}$ from racemic $\mathrm{AC}$. Thus the meso-BDH and $\mathrm{GDH}$ would be the enzymes for the meso-2,3-BD and $(2 R, 3 R)$ 2,3-BD production in strain 10-1-A, respectively.

\section{Conclusions}

In the present work, a GRAS thermophilic strain, B. licheniformis 10-1-A, was isolated for 2,3-BD production at $50^{\circ} \mathrm{C}$. This strain produced meso-2,3-BD and $(2 R, 3 R)-2,3-\mathrm{BD}$ as the major product. The key enzymes for meso-2,3-BD and $(2 R, 3 R)-2,3-\mathrm{BD}$ production were studied. In a 5 -L fed-batch fermentation of $B$. licheniformis 10-1-A, $115.7 \mathrm{~g} / \mathrm{L}$ of 2,3-BD was produced in $48 \mathrm{~h}$. The fermentation process exhibited rather high yield and productivity of 2,3-BD, indicating that B. licheniformis 10-1-A might be a promising 2,3-BD producer.

\section{Materials and methods Materials}

$(2 R, 3 R)-2,3-\mathrm{BD}$ (98.0\%), (2S,3S)-2,3-BD (99.0\%), and meso2,3-BD (98.0\%) were purchased from ACROS (The Kingdom of Belgium). CSLP was purchased from Shanghai Xiwang Starch Sugar CO., Ltd (Shanghai, China). All other chemicals were of analytical grade and commercially available.

\section{Isolation of bacteria for 2,3-BD production}

Soil samples were collected from various areas, including farmland, gardens and orchard lands. Approximately $5 \mathrm{~g}$ of each was enriched in $100 \mathrm{~mL}$ of MRS medium $(50 \mathrm{~g} / \mathrm{L}$ of glucose) and incubated at $50^{\circ} \mathrm{C}$ with agitation for $12 \mathrm{~h}$. An aliquot of the broth was plated on MRS agar medium (18 g/L of agar) and cultivated at $50^{\circ} \mathrm{C}$ for $12 \mathrm{~h}$. Based on colony type and size, representative colonies were selected and maintained in $100 \mathrm{~mL}$ MRS medium. After $8 \mathrm{~h}$ of incubation at $50^{\circ} \mathrm{C}$, the strains that are VogesProskauer-positive were selected in the medium containing (g/L): glucose 120 , YE 5 , peptone 10 , beef extract 10, triammonium citrate 2, sodium acetate 4, $\mathrm{K}_{2} \mathrm{HPO}_{4} \cdot 3 \mathrm{H}_{2} \mathrm{O} 2, \mathrm{MgSO}_{4} \cdot 7 \mathrm{H}_{2} \mathrm{O} 0.2$ at pH 7.0. After $30 \mathrm{~h}$ of incubation at $50^{\circ} \mathrm{C}$, the strain produced the highest concentration of 2,3-BD, designated as 10-1-A, was selected for further analysis.

\section{Microorganism and culture conditions}

Strain 10-1-A was maintained on MRS agar slants. The slants were incubated at $50^{\circ} \mathrm{C}$ and the fully grown slants were stored at $4^{\circ} \mathrm{C}$. The medium for inoculation contained (g/L): glucose 50.0, peptone 10.0, YE 5, NaCl 10.0. The seed culture was prepared as follows: a loop of cells from the fully grown slant was inoculated into $100 \mathrm{~mL}$ of the above medium in 500-mL Erlenmeyer flasks and incubated at $50^{\circ} \mathrm{C}$ for $12 \mathrm{~h}$ with agitation. Then the seed culture was inoculated into Erlenmeyer flasks or bioreactors (inoculum volume at 5\%) for 2,3-BD production.

\section{Genetic and physiological characterization}

The partial 16S rDNA was amplified by Polymerase Chain Reaction (PCR) from the genome of strain 10-1-A using primers $27 \mathrm{~F}$ and 1492R. The primers were as follows: $27 \mathrm{~F}$, 5'-GAGAGTTTGATCCTGGCTCAG-3' and 1492R, 5'ACGGCTACCTTGTTACGACTT-3'. The PCR program 
consisted of 30 repetitive cycles with a strand separation step at $94^{\circ} \mathrm{C}$ for $30 \mathrm{~s}$, an annealing step at $55^{\circ} \mathrm{C}$ for $30 \mathrm{~s}$ and an elongation step at $72^{\circ} \mathrm{C}$ for $30 \mathrm{~s}$. The biochemical and physiological characteristics of strain 10-1-A, such as starch hydrolysis, the VP reaction, growth in $6.5 \% \mathrm{NaCl}$ and at $55^{\circ} \mathrm{C}$, were determined step by step according to Bergey's manual of Determinative Bacteriology [35].

\section{Optimization of fermentation temperature and initial glucose concentration}

The optimal fermentation temperature of strain 10-1-A was tested using the medium contained (g/L): glucose 90 , peptone 10, YE 5, beef extract 10.0, triammonium citrate 2.0, sodium acetate 4.0, $\mathrm{K}_{2} \mathrm{HPO}_{4} \cdot 3 \mathrm{H}_{2} \mathrm{O} 2.0, \mathrm{MgSO}_{4} \cdot 7 \mathrm{H}_{2} \mathrm{O}$ 0.2. Fermentations were conducted in 500-mL Erlenmeyer flasks containing $100 \mathrm{~mL}$ of medium with shaking at $180 \mathrm{rpm}$ on a rotary shaker. After $24 \mathrm{~h}$ of fermentation at $37^{\circ} \mathrm{C}, 42^{\circ} \mathrm{C}, 50^{\circ} \mathrm{C}, 55^{\circ} \mathrm{C}$ and $60^{\circ} \mathrm{C}$, respectively, samples were taken and subjected for assay of 2,3-BD.

The following medium that contained $(\mathrm{g} / \mathrm{L})$ : peptone 10.0, YE 5.0, beef extract 10.0, triammonium citrate 2.0, sodium acetate $4.0, \mathrm{~K}_{2} \mathrm{HPO}_{4} \cdot 3 \mathrm{H}_{2} \mathrm{O} 2.0, \mathrm{MgSO}_{4} \cdot 7 \mathrm{H}_{2} \mathrm{O} 0.2$ was used to study the optimal initial glucose concentration. The experiments were conducted in $100 \mathrm{~mL}$ of each medium with initial glucose concentrations at 64.0, 91.0, 125.0, 154.0 and $180.0 \mathrm{~g} / \mathrm{L}$ and shaken at $180 \mathrm{rpm}$ on a rotary shaker. Samples were taken at 9, 13, 17 and $22 \mathrm{~h}$ and the concentrations of residual glucose and produced 2,3-BD were determined.

\section{Selection of organic nitrogen source}

For selection of organic nitrogen source, the following medium that contained $(\mathrm{g} / \mathrm{L})$ : glucose 90, triammonium citrate 2 , sodium acetate $4, \mathrm{~K}_{2} \mathrm{HPO}_{4} \cdot 3 \mathrm{H}_{2} \mathrm{O} 2$, $\mathrm{MgSO}_{4} \cdot 7 \mathrm{H}_{2} \mathrm{O} \quad 0.2$, was used. The organic nitrogens source used were as follows: $1,0.5 \% \mathrm{YE}, 1 \%$ peptone and $1 \%$ beef extract; $2,1 \%$ CSLP; $3,1 \%$ CSLP and $0.5 \%$ YE; $4,1 \%$ CSLP and $0.5 \%$ peptone; $5,1 \%$ CSLP and $0.5 \%$ beef extract. The experiments were conducted in 500$\mathrm{mL}$ Erlenmeyer flasks containing $100 \mathrm{~mL}$ of each medium with shaking at $180 \mathrm{rpm}$ on a rotary shaker at $50^{\circ} \mathrm{C}$. Samples were taken after $24 \mathrm{~h}$ and the concentrations of 2,3-BD were determined.

\section{Statistical optimization of fermentation medium}

Plackett-Burman design, an efficient technique for medium component optimization, was used to pick factors that significantly influenced 2,3-BD production, and insignificant factors that should be eliminated to obtain a smaller, more manageable set of factors. A 12-run Plackett-Burman design was used to screen six factors. The experimental responses were analyzed by the method of least squares to fit the following first-order model:

$$
\begin{aligned}
Y= & \beta_{0}+\beta_{1} X_{1}+\beta_{2} X_{2}+\beta_{3} X_{3}+\beta_{4} X_{4}+\beta_{5} X_{5} \\
& +\beta_{6} X_{6}
\end{aligned}
$$

where $Y$ was the predicted response (2,3-BD concentration), $\beta_{0}, \beta_{1}, \beta_{2}, \beta_{3}, \beta_{4}, \beta_{5}$, and $\beta_{6}$ were the regression coefficients, and $X_{1}, X_{2}, X_{3}, X_{4}, X_{5}$, and $X_{6}$ were the coded levels of the independent variables.

Based on the first-order model equation obtained by the Plackett-Burman design, a series of trials were performed in the direction of the steepest ascent. To fit the empiric second-order polynomial model, a CCD with five coded levels was performed. The quadratic model for predicting the optimal point was expressed according to the following equation:

$$
\begin{aligned}
Y= & \beta_{0}+\beta_{1} X_{1}+\beta_{2} X_{2}+\beta_{3} X_{3}+\beta_{11} X_{1}^{2} \\
& +\beta_{22} X_{2}^{2}+\beta_{33} X_{3}^{2}+\beta_{12} X_{1} X_{2}+\beta_{23} X_{2} X_{3} \\
& +\beta_{13} X_{1} X_{3}
\end{aligned}
$$

where $Y$ was predicted response (2,3-BD concentration); $\beta_{0}$ was intercept; $\beta_{1}, \beta_{2}$, and $\beta_{3}$ were linear coefficients, $\beta_{11}, \beta_{22}$, and $\beta_{33}$ were squared coefficients; $\beta_{12}, \beta_{23}$, and $\beta_{13}$ were interaction coefficients, and $X_{1}, X_{2}$ and $X_{3}$ were the coded levels of the independent variables. SAS package (version 9.0, SAS Institute, Cary, USA) was used for all the statistical analysis and the response surface plotting. Besides the studied components, the fermentation media of all the statistical optimization experiments contained about $90 \mathrm{~g} / \mathrm{L}$ of glucose.

All of the experiments mentioned above were conducted in 500-mL Erlenmeyer flasks containing $100 \mathrm{~mL}$ of each medium with shaking at $180 \mathrm{rpm}$ on a rotary shaker at $50^{\circ} \mathrm{C}$. Samples were taken at $24 \mathrm{~h}$ and the concentrations of 2,3-BD were determined.

\section{Batch and fed-batch fermentations}

Batch and fed-bacth fermentations were conducted in a 1-L bioreactor (Infors AG, Bottmingen, Switzerland) with $0.8 \mathrm{~L}$ initial medium or 5-L bioreactor (BIOSTAT B, B. Braun Biotech International GmbH, Germany) with 4 L initial medium, respectively. The seed culture prepared as mentioned above was inoculated $(5 \%, \mathrm{v} / \mathrm{v})$ into the optimized fermentation medium. The cultivation was carried out at $50^{\circ} \mathrm{C}$, stirring at $400 \mathrm{rpm}$, and airflow at $1.0 \mathrm{vvm}$. The $\mathrm{pH}$ was maintained by automatic addition of $6 \mathrm{M} \mathrm{NaOH}$ and $6 \mathrm{M}$ acetic acid using a program-controlled peristaltic pump. Samples were collected periodically to determine the biomass, concentrations of glucose, 2,3-BD and by-products.

\section{Expression and purification of meso-BDH and GDH}

The primers, $\mathrm{B} 1$ and $\mathrm{B} 2$, were used to obtain the $b d h$ gene from strain 10-1-A While G1and G2 were used to obtain 
the gdh gene. B1 with an EcoRI restriction site insertion and B2 with a SalI restriction site insertion were as follows: B1, 5'CGAATTCAATGAGTAAAGTATCTGGAA A3' and B2, 5'GTCGACTTAATTAAATACCATTCC GC3'. G1 with a BamHI restriction site insertion and G2 with a HindIII restriction site insertion were as follows: G1, 5'TGGATCCAATGTCAAAATCAGTAAAATCAG3' and G2, 5'AAGCTTTTAATCGTGATAAGATTCTGC3'. The genes were amplified by Polymerase Chain Reaction from the genome of strain 10-1-A using B1, B2, G1, and G2. The PCR program consisted of 30 repetitive cycles with a strand separation step at $94^{\circ} \mathrm{C}$ for $30 \mathrm{~s}$, an annealing step at $60^{\circ} \mathrm{C}$ for $30 \mathrm{~s}$ and an elongation step for $30 \mathrm{~s}$ at $72^{\circ} \mathrm{C}$, and then the gene was ligated to the pEASY-Blunt vector (Transgen, China). The constructed vector was named pEASY-Blunt-bdh and sequenced (Sangon, Shanghai, China). To construct the $b d h$ expression vector under the control of promoter T7, pEASY-Blunt- $b d h$ was digested with EcoRI and SalI, and the gel-purified bdh fragment was ligated to the pETDuet-1 vector digested with the same restriction enzymes. The resulting plasmid was designated pETDuet- $b d h$. The pETDuet-gdh plasmid was obtained by the same way.

Recombinant E. coli cells were grown at $37^{\circ} \mathrm{C}$ on a rotary shaker $(180 \mathrm{rpm})$ in LB medium containing ampicillin $(100 \mu \mathrm{g} / \mathrm{mL})$ to an $\mathrm{OD}_{620 \mathrm{~nm}}$ of 0.6 . Expression of the recombinant gene was induced by adding $1 \mathrm{mM}$ IPTG at $16^{\circ} \mathrm{C}$ to avoid the formation of inactive inclusion bodies for about $10 \mathrm{~h}$. After induction, the cells were harvested by centrifugation at $6,000 \times g$ for $5 \mathrm{~min}$ at $4^{\circ} \mathrm{C}$ and then washed twice with $0.85 \% \mathrm{NaCl}$. The harvested cells were resuspended in binding buffer, containing $20 \mathrm{mM}$ potassium phosphate, $500 \mathrm{mM} \mathrm{NaCl}, 20 \mathrm{mM}$ imidazole, $0.1 \mathrm{mM}$ PMSF, and $1 \mathrm{mM}$ dithiothreitol at $\mathrm{pH} 7.4$, and were disrupted by sonication in an ice bath. The homogenate was centrifuged at $15,000 \times g$ for $30 \mathrm{~min}$, and the supernatant (crude extract) was recovered. Crude extract was loaded on a $5 \mathrm{~mL}$ HisTrap HP column (GE Healthcare, USA), which had been equilibrated with $25 \mathrm{~mL}$ binding buffer. The column was washed with binding buffer, and proteins were then eluted with $10 \%, 60 \%$, and $100 \%$ elution buffer, containing $20 \mathrm{mM}$ potassium phosphate buffer, $500 \mathrm{mM} \mathrm{NaCl}$, and $500 \mathrm{mM}$ imidazole (pH 7.4). The $60 \%$ fraction was collected, concentrated, and desalted in an Amicon Ultra-15 Centrifugal Filter Units $(10 \mathrm{kDa})$ with $50 \mathrm{mM}$ Tris- $\mathrm{HCl}$ (pH 7.4). The expressed and purified enzymes were determined by SDS-PAGE.

\section{Analytical methods}

Samples were withdrawn periodically and centrifuged at $12,000 \times g$ for $10 \mathrm{~min}$. The concentration of glucose was measured enzymatically by a bio-analyzer (SBA-40D, Shandong Academy of Sciences, China) after diluting to an appropriate concentration. The analytical methods of the concentration and the stereoisomers of 2,3-BD were the same as that described in Ma et al. [8], and Xiao et al. [24]. The concentrations of by-products including acetic acid, formic acid, lactic acid and ethanol, were measured by high-performance liquid chromatography (HPLC, Agilent 1100 series, Hewlett-Packard), equipped with a Bio-Rad Aminex HPX-87H column $(300 \times 7.8 \mathrm{~mm})$ and a refractive index detector as described in Li et al. [21].

\section{Additional files}

Additional file 1: Figure S1. Multiple sequence alignment and phylogenetic tree analysis of the enzymes for 2,3-BD production in strain 10-1-A and the reported 2,3-butanediol dehydrogenases (BDHs).

Additional file 2: Figure S2. The alsSD operon in different strains.

\section{Competing interests}

The authors declare that they have no competing interests.

\section{Authors' contributions}

$L L, C M$ and $P X$ designed the study. $L L, L Z, K L Y W$, and $B H$ executed the experimental work. $L L, Y W$, and $C G$ analysed the data. $C M, C G$ and $P X$ contributed reagents and materials. $L L, C G, C M$ and PX wrote and revised the manuscript. All authors read and approved the final manuscript.

\section{Acknowledgements}

This work was supported by Chinese National Program for High Technology Research and Development (2011AA02A207), Program for High Technology Research and Development of Shandong Province (2012GSF12119).

Received: 29 June 2013 Accepted: 20 August 2013

Published: 28 August 2013

\section{References}

1. Kopke M, Mihalcea C, Liew F, Tizard JH, Ali MS, Conolly JJ, Al-Sinawi B, Simpson SD: 2,3-Butanediol production by acetogenic bacteria, an alternative route to chemical synthesis, using industrial waste gas. Appl Environ Microbiol 2011, 77:5467-5475.

2. Syu MJ: Biological production of 2,3-butanediol. Appl Microbiol Biotechnol 2001, 55:10-18.

3. Ji XJ, Huang $H$, Ouyang PK: Microbial 2,3-butanediol production: a state-of-the-art review. Biotechnol Adv 2011, 29:351-364.

4. Celińska E, Grajek W: Biotechnological production of 2,3-butanediol-current state and prospects. Biotechnol Adv 2009, 27:715-725.

5. Yan Y, Lee CC, Liao JC: Enantioselective synthesis of pure (R, R)-2,3-butanediol in Escherichia coli with stereospecific secondary alcohol dehydrogenases. Org Biomol Chem 2009, 7:3914-3917.

6. Gubbels E, Jasinska-Walc L, Koning CE: Synthesis and characterization of novel renewable polyesters based on 2,5-furandicarboxylic acid and 2,3-butanediol. J Polym Sci Pol Chem 2013, 51:890-898.

7. Ji XJ, Huang H, Du J, Zhu JG, Ren LJ, Hu N, Li S: Enhanced 2,3-butanediol production by Klebsiella oxytoca using a two-stage agitation speed control strategy. Bioresour Technol 2009, 100:3410-3414.

8. Ma C, Wang A, Qin J, Li L, Ai X, Jiang T, Tang H, Xu P: Enhanced 2,3-butanediol production by Klebsiella pneumoniae SDM. Appl Microbiol Biotechnol 2009, 82:49-57.

9. Zhang L, Sun J, Hao Y, Zhu J, Chu J, Wei D, Shen Y: Microbial production of 2,3-butanediol by a surfactant (serrawettin)-deficient mutant of Serratia marcescens H30. J Ind Microbiol Biotechnol 2010, 37:857-862.

10. Jurchescu IM, Hamann J, Zhou X, Ortmann T, Kuenz A, Prüße U, Lang S: Enhanced 2,3-butanediol production in fed-batch cultures of free and immobilized Bacillus licheniformis DSM 8785. Appl Microbiol Biotechnol 2013, 97:6715-6723.

11. Häßler T, Schieder D, Pfaller R, Faulstich M, Sieber V: Enhanced fed-batch fermentation of 2,3-butanediol by Paenibacillus polymyxa DSM 365. Bioresour Technol 2012, 124:237-244. 
12. Yang $T$, Rao Z, Zhang $X$, Lin Q, Xia H, Xu Z, Yang S: Production of 2,3-butanediol from glucose by GRAS microorganism Bacillus amyloliquefaciens. J Basic Microbiol 2011, 51:650-658

13. Biswas $R$, Yamaoka M, Nakayama H, Kondo T, Yoshida K, Bisaria VS, Kondo A: Enhanced production of 2,3-butanediol by engineered Bacillus subtilis. Appl Microbiol Biotechnol 2012, 94:651-658.

14. Ng CY, Jung MY, Lee J, Oh MK: Production of 2,3-butanediol in Saccharomyces cerevisiae by in silico aided metabolic engineering Microb Cell Fact 2012, 11:68.

15. Wang Q, Chen T, Zhao X, Chamu J: Metabolic engineering of thermophilic Bacillus licheniformis for chiral pure D-2,3-butanediol production. Biotechnol Bioeng 2012, 109:1610-1621.

16. Payot T, Chemaly Z, Fick M: Lactic acid production by Bacillus coagulans-kinetic studies and optimization of culture medium for batch and continuous fermentations. Enzyme Microb Technol 1999, 24:191-199.

17. Xiao Z, Wang X, Huang Y, Huo F, Zhu X, Xi L, Lu JR: Thermophilic fermentation of acetoin and 2,3-butanediol by a novel Geobacillus strain. Biotechnol Biofuels 2012, 5:88.

18. Zhang L, Xu Q, Zhan S, Li Y, Lin H, Sun S, Sha L, Hu K, Guan X, Shen Y: A new $\mathrm{NAD}(\mathrm{H})$-dependent meso-2,3-butanediol dehydrogenase from an industrially potential strain Serratia marcescens H30. Appl Microbiol Biotechnol. doi:10.1007/s00253-013-4959-x.

19. Yu B, Sun J, Bommareddy RR, Song L, Zeng AP: Novel (2R,3R)-2,3-butanediol dehydrogenase from potential industrial strain Paenibacillus polymyxa ATCC 12321. App/ Environ Microbiol 2011, 77:4230-4233.

20. González E, Fernández MR, Larroy $C$, Solà L, Pericàs MA, Parés $X$, Biosca JA: Characterization of a $(2 R, 3 R)$-2,3-butanediol dehydrogenase as the Saccharomyces cerevisiae YAL060W gene product. Disruption and induction of the gene. J Biol Chem 2000, 275:35876-35885.

21. Li L, Wang Y, Zhang L, Ma C, Wang A, Tao F, Xu P: Biocatalytic production of (2S,3S)-2,3-butanediol from diacetyl using whole cells of engineered Escherichia coli. Bioresour Technol 2012, 115:111-116.

22. Nicholson WL: The Bacillus subtilis ydjL (bdhA) gene encodes acetoin reductase/ 2,3-butanediol dehydrogenase. Appl Environ Microbiol 2008, 74:6832-6838.

23. Ui S, Okajima Y, Mimura A, Kanai H, Kobayashi T, Kudo T: Sequence analysis of the gene for and characterization of D-acetoin forming meso-2,3-butanediol dehydrogenase of Klebsiella pneumoniae expressed in Escherichia coli. J Ferment Bioeng 1997, 83:32-37.

24. Xiao Z, Lv C, Gao C, Qin J, Ma C, Liu Z, Liu P, Li L, Xu P: A novel whole-cell biocatalyst with $\mathrm{NAD}^{+}$regeneration for production of chiral chemicals. Plos One 2010, 5:e8860.

25. Yamada-Onodera K, Yamamoto H, Emoto E, Kawahara N, Tani Y: Characterisation of glycerol dehydrogenase from a methylotrophic yeast, Hansenula polymorpha DI-1, and its gene cloning. Acta Biotechnol 2002, 22:337-353.

26. Elibol M: Optimization of medium composition for actinorhodin production by Streptomyces coelicolor A3(2) with response surface methodology. Process Biochem 2004, 39:1057-1062.

27. Li L, Su F, Wang Y, Zhang L, Liu C, Li J, Ma C, Xu P: Genome sequences of two thermophilic Bacillus licheniformis strains, efficient producers of platform chemical 2,3-butanediol. J Bacteriol 2012, 194:4133-4134.

28. Qin J, Zhao B, Wang X, Wang L, Yu B, Ma Y, Ma C, Tang H, Sun J, Xu P: Non-sterilized fermentative production of polymer-grade L-lactic acid by a newly isolated thermophilic strain Bacillus sp. 2-6. PLoS One 2009, 4:e4359.

29. Wang Q, Zhao X, Chamu J, Shanmugam KT: Isolation, characterization and evolution of a new thermophilic Bacillus licheniformis for lactic acid production in mineral salts medium. Bioresour Technol 2011, 102:8152-8158.

30. Shaw AJ, Podkaminer KK, Desai SG, Bardsley JS, Rogers SR, Thorne PG, Hogsett DA, Lynd LR: Metabolic engineering of a thermophilic bacterium to produce ethanol at high yield. Proc Natl Acad Sci USA 2008, 105:13769-13774.

31. Nilegaonkar S, Bhosale SB, Kshirsagar DC, Kapadi AH: Production of 2,3butanediol from glucose by Bacillus licheniformis. World J Microbiol Biotechnol 1992, 8:378-381.

32. Ji XJ, Huang H, Zhu JG, Ren LJ, Nie ZK, Du J, Li S: Engineering Klebsiella oxytoca for efficient 2,3-butanediol production through insertional inactivation of acetaldehyde dehydrogenase gene. Appl Microbiol Biotechnol 2010, 85:1751-1758.

33. Wang A, Xu Y, Ma C, Gao C, Li L, Wang Y, Tao F, Xu P: Efficient 2,3-butanediol production from cassava powder by a crop-biomass-utilizer, Enterobacter cloacae subsp. dissolvens SDM. PLoS One 2012, 7:e40442.
34. Najmudin S, Andersen JT, Patkar SA, Borchert TV, Crout DH, Fülöp V: Purification, crystallization and preliminary X-ray crystallographic studies on acetolactate decarboxylase. Acta Crystallogr D Biol Crystallogr 2003, 59:1073-1075.

35. Buddingh GJ: Bergey's manual of determinative bacteriology. 8th edition. Maryland: The Williams and Wilkins Company; 1974.

doi:10.1186/1754-6834-6-123

Cite this article as: Li et al.: A newly isolated Bacillus licheniformis strain thermophilically produces 2,3-butanediol, a platform and fuel biochemical. Biotechnology for Biofuels 2013 6:123.

\section{Submit your next manuscript to BioMed Central and take full advantage of:}

- Convenient online submission

- Thorough peer review

- No space constraints or color figure charges

- Immediate publication on acceptance

- Inclusion in PubMed, CAS, Scopus and Google Scholar

- Research which is freely available for redistribution

Submit your manuscript at www.biomedcentral.com/submit
C) Biomed Central 